\title{
Improvement in Children's Mental Health and Cognitive Abilities with Yogic Breathing: A Pilot Study
}

\author{
Divya Kanchibhotla', Saumya Subramanian ${ }^{2}$ \\ ${ }^{1}$ Executive Director, ${ }^{2}$ Research Associate, Sri Sri Institute for Advanced Research, Bangalore, Karnataka, India. \\ DOI: https://doi.org/10.24321/2349.2880.202108
}

I $\mathbf{N}$ F $\mathbf{O}$

\section{Corresponding Author:}

Divya Kanchibhotla, Sri Sri Institute for Advanced

Research, Bangalore, Karnataka, India.

E-mail Id:

director.ssiar@artofliving.org

Orcid Id:

https://orcid.org/0000-0002-0760-630X

How to cite this article:

Kanchibhotla D, Subramanian S. Improvement in Children's Mental Health and Cognitive Abilities with Yogic Breathing: A Pilot Study. Ind J Youth Adol Health. 2021;8(3):1-4

Date of Submission: 2021-08-17

Date of Acceptance: 2021-09-25

\section{$\begin{array}{llllllll}\mathbf{A} & \mathbf{B} & \mathbf{S} & \mathbf{T} & \mathbf{R} & \mathbf{A} & \mathbf{C} & \mathbf{T}\end{array}$}

Introduction: Children as young as 6 or 7 years old face numerous stressful situations at home and outside their homes. During this time, when learning and growth should be the priority, young minds often struggle with constant pressure to compete with their peers in their academic careers. This study examines the effects of a breath-based yogic technique in improving the child's mental health and cognition.

Method: A study was conducted among the students who underwent the yogic breathing workshop (Utkarsha Yoga). Cognition was measured using the six-letter cancellation test (SCLT). The mental well-being of the students was assessed using the World Health Organization well-being index (WHO-5) and the Child Perceived Stress Scale (C-PSS).

Results: $73 \%$ of the population showed a significant improvement in the mental well-being post-workshop. $56 \%$ of the population experienced a significant decrease in stress levels post yogic breathing intervention and by following the programme, the cognitive abilities improved by $27 \%$ in children.

Conclusion: The results for this pilot study demonstrate the Yogic Breathing Technique (YBT) to be an effective tool for children to develop a calm and happy state of mind.

Keywords: Yoga, Mental health, Cognition, Breathing

\section{Introduction}

Child and adolescent mental health is a global concern. According to the Centre for Disease Control and Prevention, USA, $7.1 \%$ and $3.2 \%$ of children suffer from anxiety and depression respectively. ${ }^{1}$ It is suspected that $25 \%$ of children and adolescents in India will continue to suffer from mental disorders for their entire life. ${ }^{2}$ In India, the prevalence of child psychiatric disorders was found to be $6.46 \%$ among the general community and $23.3 \%$ among school-going children. ${ }^{2}$ Studies indicate a correlation between poor mental health, cognitive impairment, and weak academic performance in children. ${ }^{3}$ Under chronic stress, changes in brain architecture especially in the prefrontal cortex, lead to decreased memory and cognitive flexibility. ${ }^{4-6}$ Studies also demonstrate a negative effect of stress on both physical and mental health, resulting in decreased academic performance among students. ${ }^{7}$

Yoga and one of its limbs, meditation have a positive effect on anxiety, depression, and self-esteem, thereby improving academic performance in students with learning 
disabilities. ${ }^{8}$ A study of 98 school-going children in urban India demonstrated the benefits of yoga and physical exercise on physical, emotional, and cognitive measures. ${ }^{9}$ Introducing yogic practices and mindfulness early in life may enhance core cognitive skills and prevent the onset of mental illness. Hence, it would be appropriate to explore the scope of yogic practices on improving child mental health and cognition. ${ }^{10}$

In India, where the academic pressure is intense, most studies that assess the impact of yogic practices on children focus on improvement in cognitive abilities. However, as is evident from many studies, Indian children are facing several mental health challenges. In this study, we investigate the immediate and sustained long term impact of a yogic breathing technique on the mental health and cognitive abilities of children.

\section{Method}

\section{Study Design}

An open trial single-arm pilot study was conducted. Children between the ages of 8-13 years who participated in a fourday workshop (Utkarsha Yoga) focusing on the body, breath, and mental wellness, at the Art of Living International Centre, Bengaluru, India, were enrolled for this study. The sample included 420 participants, among whom, 237 were male and 183 were female. The workshop was taught by experienced yoga trainers. The mean age of the population was 10.5 years. Informed consent was sought from the participants' parents at the beginning of the programme. Data collection was done between April 2019 and June 2019. Data were collected by the team of Sri Sri Institute for Advanced Research, consisting of members who were not involved in delivery of the intervention. Ethical approval was obtained from the Institutional Ethics Committee (Sri Sri Institute for Advanced Research) bearing registration number SSIAR/IEC/07. Due to technical issues, the trial was not registered in CTRI.

\section{Intervention}

The retreat was designed as a four-day residential programme. It incorporated yoga postures and yogic breathing techniques which included Sudarshan Kriya, a rhythmic breathing technique that incorporates specific natural rhythms of the breath, harmonising the body, mind, and emotions, thus facilitating physical, mental, emotional, and social well-being, which is an integral part of the Art of Living programmes to prepare the mind and body for meditation.

\section{Measures}

Assessment of mental health of the participants was done using the Child Perceived Stress scale (Child-PSS) and World Health Organization Well-Being Index WHO-5. Since all the children who participated in the study hailed from an urban area and were from an English medium school, they were comfortable in English. Therefore, all the assessments were done in the English language only and no translation was required. Child PSS is a 14 item questionnaire measuring stress perception ${ }^{11}$ among children. WHO-5 is a 5 -item global rating scale measuring subjective well-being. ${ }^{12}$ Three different time points for assessment were implemented viz. pre-intervention (day 0), post-intervention (day 4), and after 40 days of practice (day 40). The cognitive abilities of participants were measured using the six-letter cancellation test, administered only at pre and post-intervention time points. ${ }^{13}$ To avoid the learning effect for SLCT, a different test was used for both time points. Analysis of the scores obtained before, after, and on day 40 of intervention was conducted using paired-sample t-test to obtain $p$ values. The difference between the scores was considered significant if the $p$-value was less than 0.05 .

\section{Results}

Table 1 depicts the WHO-5 scores which represent the mental well-being of participants at different time points. The results indicate a significant increase in the mental well-being post-intervention $(p<0.001)$ for both genders. This improvement was sustained on day 40 of practice.

Table I.Pre-post Analysis of WHO-5 Wellbeing Index among the Study Group

\begin{tabular}{|c|c|c|c|c|c|}
\hline & Pre & Post & $\begin{array}{c}\text { Day } \\
\mathbf{4 0}\end{array}$ & $\begin{array}{c}\text { p-value } \\
\text { pre-post }\end{array}$ & $\begin{array}{c}\text { p-value } \\
\text { pre-day 40 }\end{array}$ \\
\hline $\begin{array}{c}\text { Mean } \\
\text { score }\end{array}$ & 17.13 & 19.7 & 19.07 & $<0.001^{* *}$ & $0.017^{*}$ \\
\hline $\begin{array}{c}\text { Male } \\
(237)\end{array}$ & 16.5 & 19.05 & 18.43 & $0.00^{* *}$ & $0.00^{* *}$ \\
\hline $\begin{array}{c}\text { Female } \\
(183)\end{array}$ & 17.88 & 20.55 & 19.67 & $0.00^{* *}$ & $0.00^{* *}$ \\
\hline
\end{tabular}

**p-value $<0.001$ - Significant *p-value $<0.05$ - Significant

Table 2.Pre-post Analysis of Child PSS Index among the Study Group

\begin{tabular}{|c|c|c|c|c|c|}
\hline & Pre & Post & Day 40 & $\begin{array}{c}\text { p-value } \\
\text { pre-post }\end{array}$ & $\begin{array}{c}\text { p-value } \\
\text { pre-day 40 }\end{array}$ \\
\hline $\begin{array}{c}\text { Mean } \\
\text { score }\end{array}$ & 7.97 & 7.4 & 5.81 & $0.003^{*}$ & $0.00^{* *}$ \\
\hline $\begin{array}{c}\text { Male } \\
(237)\end{array}$ & 7.9 & 7.74 & 6.16 & $<0.001^{* *}$ & $<0.001^{* *}$ \\
\hline $\begin{array}{c}\text { Female } \\
(183)\end{array}$ & 8.04 & 7.04 & 5.83 & $<0.001^{* *}$ & $<0.001^{* *}$ \\
\hline
\end{tabular}

Table 2 depicts the Child PSS scores pre-post intervention. Stress levels among students dropped after the practice of yogic breathing and the effect was sustained at day 40 . 
Table 3.Average Accuracy for Six Letter Cancellation Test

\begin{tabular}{|c|c|c|c|}
\hline & $\begin{array}{c}\text { Pre- } \\
\text { intervention }\end{array}$ & $\begin{array}{c}\text { Post- } \\
\text { intervention }\end{array}$ & p-value \\
\hline $\begin{array}{c}\text { Total } \\
\text { population }\end{array}$ & $34.59(14.009)$ & $\begin{array}{c}43.91 \\
(16.28)\end{array}$ & $<0.001^{* *}$ \\
\hline Male & $32.05(13.46)$ & $\begin{array}{c}42.87 \\
(16.77)\end{array}$ & $<0.001^{* *}$ \\
\hline Female & $37.54(14.19)$ & $\begin{array}{c}44.98 \\
(15.67)\end{array}$ & $<0.001^{* *}$ \\
\hline
\end{tabular}

$* * p$-value $<0.001$ - Significant

Table 3 lists the accuracy percentage for SLCT which is representative of a student's cognitive abilities. Accuracies improved after the intervention and a significant improvement was noticed in the performance of the participants ( $p$-value $<0.001$ ).

Table 4.Effect Size of the Intervention between the Time Points

\begin{tabular}{|c|c|c|}
\hline Cohen's D & Pre-Post & Pre-D40 \\
\hline PSS & 0.152 & 0.567 \\
\hline WHO5 & -0.671 & -0.381 \\
\hline Six letter & -0.606 & \\
\hline
\end{tabular}

The effect size of the intervention on Child-PSS, as calculated by Cohen's value on Child-PSS, was found to be 0.152 , implying that $56 \%$ of participants were stressed before the intervention programme as compared to after the programme.

The effect size of the intervention on mental well-being, as calculated by Cohen's value on WHO-5, was found to be 0.671 , implying that $73 \%$ of participants were below average in terms of wellness index before the intervention programme as compared to after the programme (Table 4).

\section{Discussion}

The present study demonstrated a correlation between yogic breathing practices, mental health, and cognition of school-going children. 420 children ( 237 male and 183 female) participated in the study. Out of the study group, 362 students were assessed for cognitive ability.

The study results showed that mental well-being is enhanced with practice and the effect is both immediate and sustained over a long term. We observed that with the yogic breathing practice, the participants' mental well-being increased and stress levels decreased. As the stress levels decreased, the accuracy of SLCT significantly improved. Although it was a residential workshop, children belonged to different groups with no prior acquaintance, but over the course of time, during the workshop, they got acquainted and sociable with one another.

Studies support that practices such as meditation enhance attention skills in children. They also improve their working memory, speed of execution, and visuospatial processing as tested by the six-letter cancellation test. ${ }^{15} \mathrm{~A}$ similar study on the impact of diaphragmatic breathing on healthy adults provided evidence of improved sustained attention and reduction in cortisol levels. ${ }^{16}$ Another study concluded that yoga when practised regularly by students, even for short intervals, improved their test performance, teacherstudent relationships, eased transitions, and reduced the need for disciplinary actions. ${ }^{17}$

Previous studies on yogic breathing techniques like Sudarshan Kriya Yoga (SKY) on adults have illuminated its benefits to combat various disorders like stress, anxiety, post-traumatic stress disorder, and depression among youngsters. ${ }^{18}$ SKY is known to enhance vagal tone and regulate parasympathetic nervous system. ${ }^{19}$ As hypothesised, our results indicate a significant improvement in the cognitive abilities expressed by the students after learning the yogic breathing technique.

The key limitation of the present study is the absence of a control group. Self-selection and related bias cannot be ruled out. Hence, further studies are required with a randomised control group to negate the effect of these confounding factors. However, this pilot study is able to demonstrate the positive effects of yogic breathing techniques on the mental well-being and cognition of children and adolescents.

\section{Conclusion}

The results of this study show that yogic breathing practices improve mental health, reduce stress, and increase cognitive abilities in adolescents. Incorporating yogic breathing practices can support students' mental health, prevent the onset of mental disorders, and improve their intellectual capacity.

\section{Acknowledgement}

We would like to acknowledge Mr. Prateek Harsora for his support in data handling and smooth execution of the project and Mr Shashank Kulkarni for statistical data analysis and data inferencing. We would also like to acknowledge and thank The Art of Living Children's and Teens desk for allowing us to conduct the study.

\section{Funding: None}

\section{Conflict of Interest: None}

\section{References}

1. CDC [Internet]. Anxiety and depression in children: Get the facts; [cited 2020 Jul 20]. Available from: https:// www.cdc.gov/childrensmentalhealth/features/anxiety- 
depression-children.html

2. Malhotra S, Patra BN. Prevalence of child and adolescent psychiatric disorders in India: a systematic review and meta-analysis. Child Adolesc Psychiatry Ment Health. 2014;8(1):1-9. [PubMed] [Google Scholar]

3. Banaeipour Z, Rostami S, Zarea K, Cheraghian B. The prevalence of anxiety and its related factors among school-age children in South West of Iran. Int J Pediatr. 2016;4(6):2019-25. [Google Scholar]

4. Pechtel P, Pizzagalli DA. Effects of early life stress on cognitive and affective function: an integrated review of human literature. Psychopharmacology (Berl). 2011;214(1):55-70. [PubMed] [Google Scholar]

5. McEwen BS, Eiland L, Hunter RG, Miller MM. Stress and anxiety: structural plasticity and epigenetic regulation as a consequence of stress. Neuropharmacology. 2012;62(1):3-12. [PubMed] [Google Scholar]

6. Cibrian-Llanderal T, Melgarejo-Gutierrez M, HernandezBaltazar D. Stress and cognition: psychological basis and support resources. In: Bernal-Morales B, editor. Health and academic achievement. IntechOpen. 2018;11-29. [Google Scholar]

7. Aafreen MM, Priya VV, Gayathri R. Effect of stress on academic performance of students in different streams. Drug Inven Today. 2018;10(9):1776-80. [Google Scholar]

8. Beauchemin J, Hutchins TL, Patterson F. Mindfulness meditation may lessen anxiety, promote social skills, and improve academic performance among adolescents with learning disabilities. Complement Health Pract Rev. 2008;13(1):34-45. [Google Scholar]

9. Telles S, Singh N, Bhardwaj AK, Kumar A, Balkrishna A. Effect of yoga or physical exercise on physical, cognitive and emotional measures in children: a randomized controlled trial. Child Adolesc Psychiatry Ment Health. 2013;7(1):1-16. [Google Scholar]

10. Seppälä EM, Bradley C, Moeller J, Harouni L, Nandamudi D, Brackett MA. Promoting mental health and psychological thriving in university students: a randomized controlled trial of three well-being interventions. Front Psychiatry. 2020;11:590. [PubMed] [Google Scholar]

11. White BP. The perceived stress scale for children: a pilot study in a sample of 153 children. Int J Paediatr Child Health. 2014;2(2):45-52. [Google Scholar]

12. Topp CW, $\varnothing$ stergaard SD, Søndergaard S, Bech P. The WHO-5 Well-Being Index: a systematic review of the literature. Psychother Psychosom. 2015;84(3):167-76. [Google Scholar]

13. Gulati K, Sharma SK, Telles S, Balkrishna A. Self-esteem and performance in attentional tasks in school children after 4 $\frac{1}{2}$ months of yoga. Int J Yoga. 2019;12(2):158. [PubMed] [Google Scholar]

14. Coe R. It's the effect size, stupid: what effect size is and why it is important. 2002 Annual Conference of the British Educational Research Association, University of Exeter, Exeter, Devon, England; 2002 Sep 12-14. [Google Scholar]

15. Zeidan F, Johnson SK, Diamond BJ, David Z, Goolkasian P. Mindfulness meditation improves cognition: evidence of brief mental training. Conscious Cogn. 2010;19(2):597-605. [PubMed] [Google Scholar]

16. Ma X, Yue ZQ, Gong ZQ, Zhang H, Duan NY, Shi YT, Wei GX, Li YF. The effect of diaphragmatic breathing on attention, negative affect and stress in healthy adults. Front Psychol. 2017;8:874. [PubMed] [Google Scholar]

17. Finnan C. Not a waste of time: scheduling non-academic learning activities into the school day. Urban Rev. 2015;47(1):26-44. [Google Scholar]

18. Pandey R, Tyagi G, Giri A. Benefits of Sudarshan Kriya (SKY) on mental wellbeing of humans. J Med Sci Clin Res. 2017 Jul;5(7):24562-6. [Google Scholar]

19. Brown RP, Gerbarg PL. Sudarshan Kriya yogic breathing in the treatment of stress, anxiety, and depression: part I-neurophysiologic model. J Altern Complement Med. 2005;11(1):189-201. [PubMed] [Google Scholar] 